\title{
Influence of the pile toe condition on the dynamic response of a group of pile foundations
}

\author{
Salah Messioud ${ }^{1} \cdot$ Daniel Dias $^{2,3} \cdot$ Badreddine Sbartai $^{4}$
}

Received: 14 December 2017 / Accepted: 1 February 2019 / Published online: 11 February 2019

(c) The Author(s) 2019

\begin{abstract}
The anchorage of the piles on a stiffer soil layer plays an important role to transmit the loads of the superstructure to the soil. Depending on the pile toe condition, three configurations of piles are considered: floating piles, rested, and anchored piles. To study the effect of the pile toe condition on the dynamic response of pile and pile groups, a three-dimensional finite element modeling of the soil-pile-slab dynamic interaction is presented. The soil and piles are represented as continuum solids and the slab by structural elements. Quiet boundaries are placed at the boundaries of the model to avoid wave reflection. The formulation is based on the substructuring method. The dynamic response is obtained in terms of the dynamic impedances. In this study the dynamic response of the floating, rested, and anchored piles are analyzed and the group effect is shown. An analysis of the horizontal and vertical pile foundation impedances is presented and the results are compared with different configurations.
\end{abstract}

Keywords Pile group $\cdot$ Dynamic impedance $\cdot$ Soil-structure interaction $\cdot$ Numerical model

\section{Introduction}

Deep foundations like piles are commonly used to ensure the stability of structures located in seismic zones. The stability of the structures is ensured in relation to the efforts or tilting induced by the seismic loading. The design and calculation of deep foundations in seismic zones involves numerous parameters especially the behavior of soil, of the piles and of the different interactions between these constituents and the structures located at the surface. A very important parameter of the soil-pile-structure interaction which should be studied is the anchoring of piles in hard soil layers (Messioud et al. 2016a). The dynamic response of rested or anchored piles is still unclear such as the substratum effect on the dynamic response of pile group foundations. Rested

Salah Messioud

smessioud@yahoo.fr

1 LGCE, University of Jijel, BP 98 Ouled Aissa, 18000 Jijel, Algeria

2 School of Automotive and Transportation Engineering, Hefei University of Technology, Hefei, China

3 Antea Group, 92160 Antony, France

4 University of Annaba, 23000 Annaba, Algeria and anchored piles on a non-deformable substratum reduce the vertical and horizontal displacements of the piles and increase the rigidity of the piles groups Messioud et al. (2016b). Okyay et al. (2012) used a series of dynamic tests conducted on an experimental site and developed numerical models to study the influence of the pile end-fixity conditions on the dynamic behavior of soil-piles-slab systems. Therefore, a thorough study of the seismic behavior of deep foundations is necessary to ensure the proper functioning of the latter system. The soil-structure interaction in dynamics is characterized by impedance functions (Kausel et al. 1978; Pecker 1984; Aubry and Clouteau 1992).

For surface foundations, simple expressions exist for the calculation of impedance functions (Wolf 1994). On the other hand, a few solutions exist for the case of pile groups (Mylonakis and Gazetas 1999). The numerical analysis of a pile or group of piles integrated in a homogeneous soil in the frequency domain is presented by several authors. Using the boundary element method, numerical models were developed and a group of piles was analyzed by Kaynia (1982) and Kaynia and Kausel (1991). Vibration isolation by a row of piles has been analyzed in Kattis et al. (1999a, b), and dynamic impedances of pile groups have been studied by Vinciprova et al. (2003) and Maeso et al. (2005) A coupling between the boundary element method and the finite element method is 
presented by Padron et al. (2007) to determine the impedance functions of a group of piles. The CIFEM method (Consistent Infinitesimal Finite Element Method) is used by Emani and Maheshwari (2009) for the calculation of the dynamic impedances of a pile group. Recently, an analytical layer-element method was applied, the responses of the piles and raft are formulated as a series of equations, the pile group in transversely isotropic soils layer Ai et al. (2016) and Liu and Ai (2017). A simplified solution procedure is proposed for estimating the dynamic response of a pile group partially embedded in a layered saturated soil and subjected to horizontal harmonic loading Liu et al. (2014). Sawant and Ladhane (2012) used the finite element method for study the dynamic response of pile groups. In this context the dynamic response of the inclined piles in time domain than in the frequency analysis was obtained by Kouroussis et al. (2013).

The pile toe condition on a stiffer soil layer plays an important role to transmit loads from the superstructure to the soil. Given the complexity of the soil-pile-slab interaction problem and the strong coupling between the different elements forming this foundation system, a three-dimensional finite element numerical modeling with absorbing boundaries is proposed. The aim of this modeling is to analysis the influence of the fixing conditions of the piles in the hard soil on the dynamic response of soil-pile-slab systems. To model the soil and piles, volumic elements are considered and the slab is considered using structural elements. The dynamic impedances are calculated from the displacements obtained at the point of application of the exciting force. Floating, rested and anchored piles in a hard soil layer are analyzed and the effect of groups is also studied. The vertical and horizontal dynamic impedance are presented for different configuration.

\section{Numerical modeling of a soil-pile-slab system}

\section{Calculation model}

In geodynamics, engineers are confronted with very large domains. The influence of the dynamic loading on the structures is often taken into account via a dynamic impedance matrix at the soil-structure interface. The terms of the impedance matrix are expressed in the form of functions with complex values of the frequency. The impedance function of a foundation can be expressed in general as follows:

$K(\omega)=K_{\mathrm{s}}\left(k+i a_{0} c\right)$ avec $a_{o}=\frac{\omega \cdot B_{\mathrm{f}}}{C_{\mathrm{s}}}$

With $a_{0}$ the dimensionless frequency defined by the characteristic dimension $B_{\mathrm{f}}$ of the foundation. For example; the radius for a circular foundation, the half width for a rectangular foundation and the diameter $\mathrm{d}$ for a pile or piles groups. $C_{\mathrm{s}}$ is the shear soil wave velocity and $\omega$ is the pulsation of the harmonic excitation.

The majority of the used methods for the determination of impedance functions are so-called the classical methods (Kattis et al. 1999a, b; Vinciprova et al. 2003; Mamoon et al. 1990; Coda et al. 1999; Coda and Venturini 1999). Boundary element method BEM, Boundary element method coupling with Finite Element Method BEM-MEF and Boundary element method coupling with Thin Layer Method BEM-TLM based on the formalism of the Green functions are often used. In this work, the finite element method is used to determine the dynamic impedance functions.

Figure 1 shows the finite element discretization of the soil-pile-slab systems. To obtain a solution in the frequency domain, the equations of the matrix relative to the forces and displacements are given by the relation:

$\left(-\omega^{2} M+i \omega C+S\right) U=P$,

where $M$ is the matrix of masses, $C$ is the matrix of damping, and $S$ is the stiffness matrix. $P$ and $U$ are the force and displacement vectors, where $\omega$ is the excitation frequency.

The dynamic impedance of the foundation is equal to the reaction exerted on the massless foundation subjected to harmonic solicitations according to the considered direction.

$[K]\{U\}=\{P\}$

With; $P_{\mathrm{i}}$ the force vector (moments) applied to the center of the slab, $U$ is the resulting displacement at the point of application of force vector and $K$ is the dynamic impedance. The dynamic impedance also represents the quotient of a force directly applied to the foundation (which is equal to the soilreaction) by the resulting displacement. The dynamic-impedance matrix is calculated using the following relation:

$K(\omega)=\frac{P_{i} \mathrm{e}^{i \omega t}}{U_{i} \mathrm{e}^{i \omega t}}$

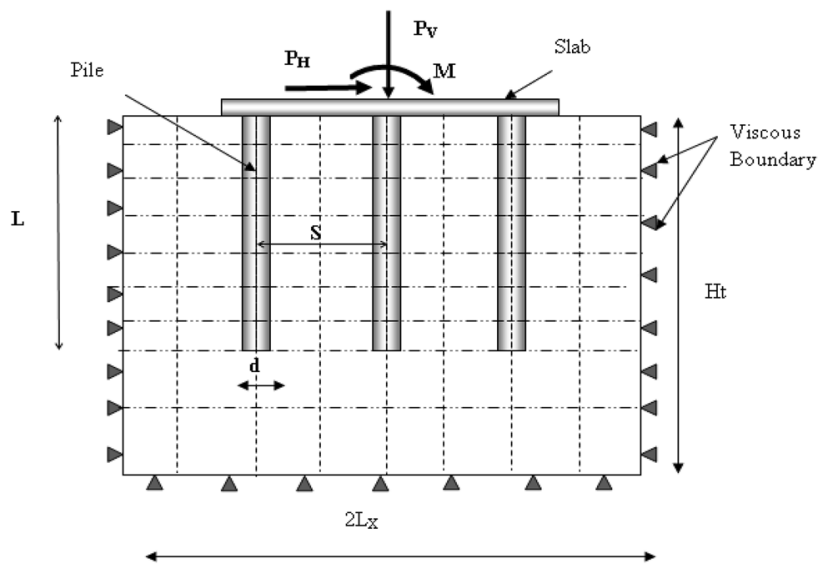

Fig. 1 Dynamic impedance solution 
For a rigid foundation with six degrees of freedom, the impedance matrix $K(w)$ have a $6 \times 6$ dimension. If the foundation is of an arbitrary shape, the different degrees of freedom are coupled and the impedance matrix is full. If the foundation has symmetries, some of the coupling terms (non-diagonal terms) can be equal to zero. The relation 4 can be written as follows:

$\left\{\begin{array}{c}P_{X} \\ M_{Y} \\ P_{Z}\end{array}\right\}=\left[\begin{array}{ccc}K_{X X} & K_{X \theta} & 0 \\ K_{\theta X} & K_{\theta \theta} & 0 \\ 0 & 0 & K_{Z Z}\end{array}\right]\left\{\begin{array}{c}U_{X} \\ \theta_{Y} \\ U_{Z}\end{array}\right\}$,

where $P_{i}=\left\{P_{X}, M_{Y}, P_{Z}\right\}$ is the vector of dynamic loading and $U_{i}=\left\{U_{X}, \theta_{Y}, U_{Z}\right\}$ the vector of the displacements. Where, subscripts $X, \theta$ and $Z$ refer to horizontal, rocking and vertical motions, respectively. The matrix $[K]$ is symmetric and the cross entries except $K_{X \theta}\left(=K_{\theta X}\right)$ in $[\mathrm{K}]$ are negligible. The dynamic impedances are presented in the form, $K_{i j}(\omega)=\left[k_{i j}^{r}(\omega)+i k_{i j}^{i}(\omega)\right]$, this expression presents a real part $k_{i j}^{r}$ and an imaginary part $i k_{i j}^{i}$, the impedance functions have been normalized with static-stiffness $\left(K_{\mathrm{s}}\right)$ or the static impedance $(\omega=0)$.

$K_{i j}(\omega)=K_{\mathrm{s}}\left[k^{\prime} i j(\omega)+i k_{i j}^{\prime \prime}(\omega)\right]$

With, $k^{\prime} i j(\omega)$ reflects the elastic behavior and takes into account the rigidity and inertia of the medium and $k_{i j}^{\prime \prime}(\omega)$ indicates the vibratory motion is damping.

The dynamic functions impedances $K_{i j}(\omega)$ obtained using a 3-D FEM formulation are analyzed in the following study. Using the sub-structuring method, the global soil-structure domain is decomposed into subdomains. Due to the wave reflection at the numerical model boundaries, the use of absorbent boundaries is necessary; paraxial elements already implemented in the Software Code-Aster were set up (CodeAster 2010).

\section{Characteristics of models}

Figure 2 shows the 3D model used for numerical simulation using the ASTER ${ }^{\circledR}$ code (Code-Aster 2010). The geometrical characteristics of the model were determined with a parametric study to ensure the correct functioning of the absorbing boundaries. The volume of soil studied is of dimensions $40 \times 40 \times 15 \mathrm{~m}^{3}$. Circular piles of reinforced concrete of length $9-11 \mathrm{~m}$ are modeled. Their diameter is equal to $0.60 \mathrm{~m}$, the length/diameter ratio is between 15 and 16.67 . The slab is not in contact with the ground and has a thickness of $0.6 \mathrm{~m}$. It is represented by shell elements. The shell elements are linked to the volumic elements of the model (piles and soil). The elements of the interacting models are considered to be linear elastic. The mechanical properties of the soil and foundation layers are presented in Table 1. The choice of these properties was made from a bibliographic search (Emani and Maheshwari 2009; Padron et al. 2007).

The choice of the model and the size of the volumic elements is in agreement with the wavelength to minimize the effect of distortion waves. The maximum size of the mesh element allowed for the proper transmission of waves is equal to $0.4 \mathrm{~m}$. Kuhlemeyer and Lysmer (1973) show that the size mesh element must be less than one tenth of the wavelength $\lambda$.

$f=\frac{C_{\mathrm{s}}}{10 \cdot \Delta l}$ with $f=\frac{\omega}{2 \pi}$

With $C_{\mathrm{s}}$ is the shear-wave velocity, $\Delta l$ the size of the mesh element and $\omega$ the frequency of excitation. The maximum frequency is depending on the maximum size of the element and the natural frequency of the soil-piles-slab system is equal to $2.50 \mathrm{~Hz}$ (Fig. 3).

\section{Results and discussion}

This work analyzes the inertial effect of the slab, the influence of the distance between the axis of the piles and the influence of the fixing conditions of the piles in the support layer (more rigid) on the vertical and horizontal dynamic impedances. The piles are floating, rested and anchored. The floating piles are implemented in the compressible soil and have a length of $9 \mathrm{~m}$ (Fig. 3a). The rested piles are $10 \mathrm{~m}$ long and rest directly on the hard soil (Fig. 3b). The anchored piles have a length of $11 \mathrm{~m}$ and are anchored at $1 \mathrm{~m}$ in the hard soil layer (Fig. 3c). The vertical and horizontal dynamic impedance of the soil-pile-slab system are calculated by applying a dynamic load in the center of the slab of the models presented in Fig. 2.

\section{Inertial effect of the slab}

When the foundation is not massless, one simply has to replace $[K]$ by $[K]-\omega^{2}[M]$ in the above equations, where $[M]$ is the mass matrix of the foundation. Figures 4 and 5 show, respectively, the variation of the vertical and horizontal dynamic impedances as a function of the frequency for a group of four floating piles (Fig. 2). The obtained results show that the inertial effect of the slab on the vertical dynamic impedances is important. The stiffness terms are strongly attenuated for $s / d$ ratios relatively high and the frequency increases in a lower manner. Concerning the damping terms, these are not affected by the inertial effect of the slab.

The obtained results show that the horizontal dynamic impedances are strongly affected by the slab inertia than the 


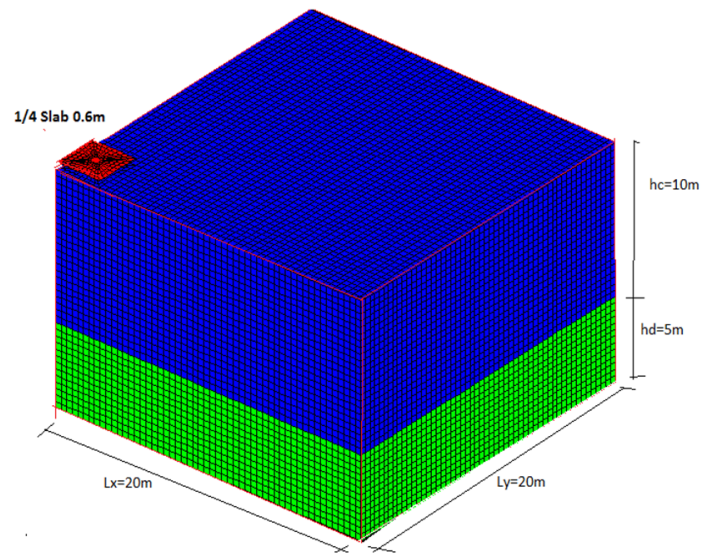

a Quarter part of the numerical model

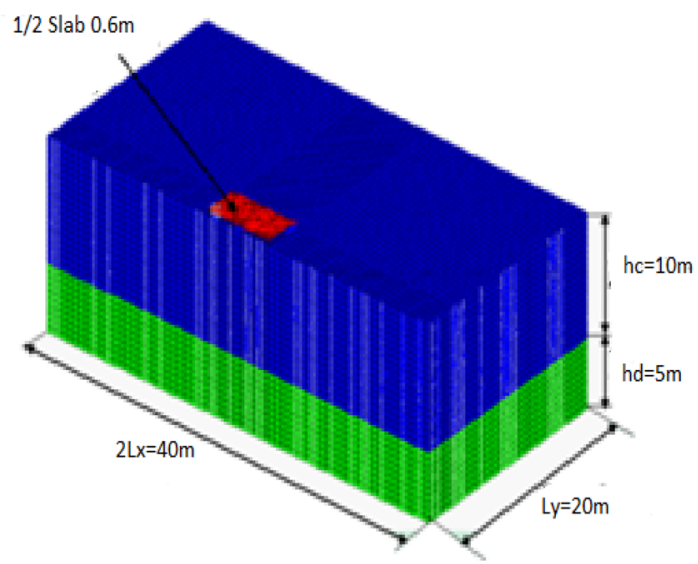

\section{c Half numerical model}

Fig. 2 Geometry of the numerical model

Table 1 Mechanical characteristics of the soil and structure elements

\begin{tabular}{|c|c|c|c|c|}
\hline & $\begin{array}{l}\text { Young } \\
\text { modulus } \\
(\mathrm{MPa})\end{array}$ & Poisson ratio & $\begin{array}{l}\text { Volumic } \\
\text { weight (kg/ } \\
\left.\mathrm{m}^{3}\right)\end{array}$ & Damping ratio \\
\hline Soft soil & 25 & 0.4 & 1800 & 0.05 \\
\hline Hard soil & 250 & 0.3 & 2200 & 0.05 \\
\hline Piles/slab & 25,000 & 0.25 & 2500 & 0.0 \\
\hline
\end{tabular}

vertical dynamic impedances (Figs. 4 and 5). The inertial effect is marked by a high attenuation for ratios $s / d=5$ and 10 relatively high. The frequency becomes smaller and lower than the one of the vertical impedances. The dynamic impedances become negative for high frequencies, caused by the increase of the vibrating mass. The percentage of attenuation

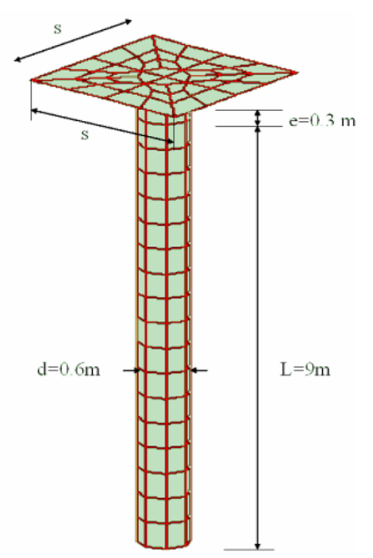

b Zoom of a pile

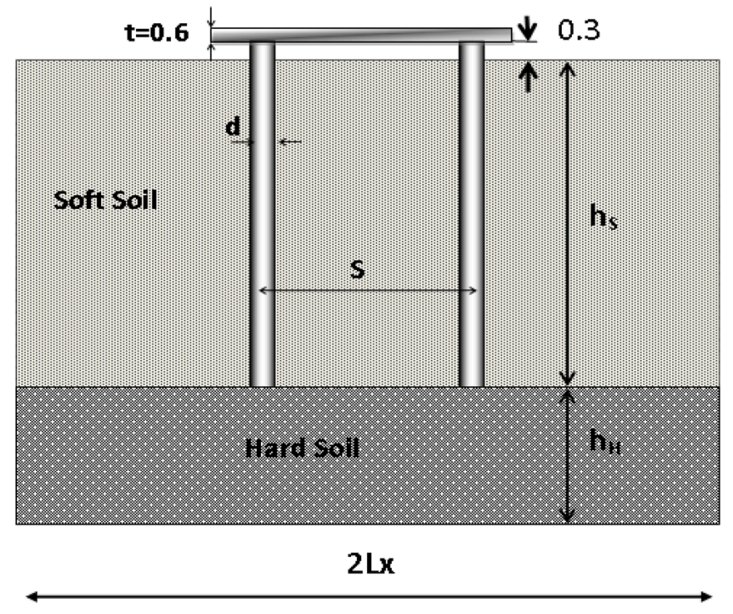

d Model geometry

(evolution rate) is very high, especially for the horizontal dynamic impedance. The variation of the dynamic impedance of the massless foundation and the other with mass is, respectively, equal to 0.98 and -12.73 (Table 2). In percentage, it represents, respectively a decrease of $1398.98 \%$ for the ratio $s / d=10$ and a decrease of $345.65 \%$ for the ration $s / d=5$. So at the frequency $20 \mathrm{~Hz}$, the decrease of the horizontal dynamic impedance (foundation with mass) is almost 13 times the value of the impedance of a massless foundation. This is not the case for the vertical dynamic impedance, the percentage of attenuation (evolution rate) is relatively low compared to the horizontal impedance. It can vary between $256 \%$ for $s / d=10$ and $70 \%$ for $s / d=5$. 


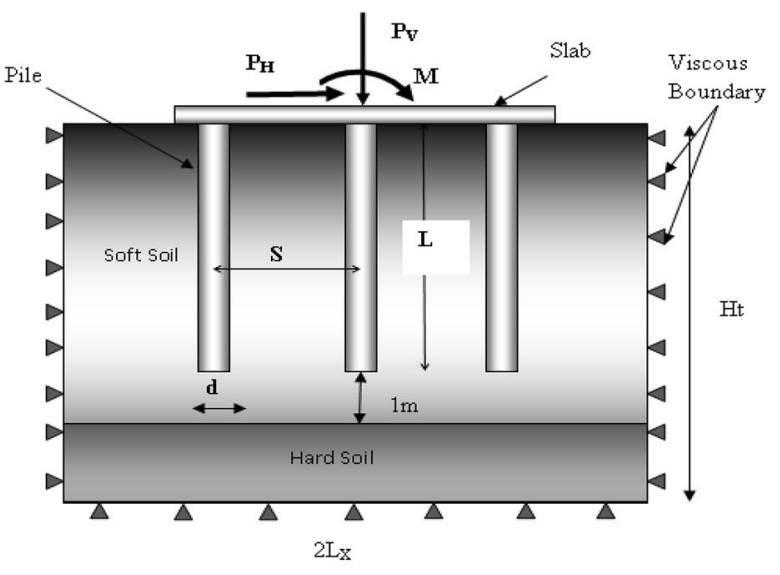

a Floating Piles

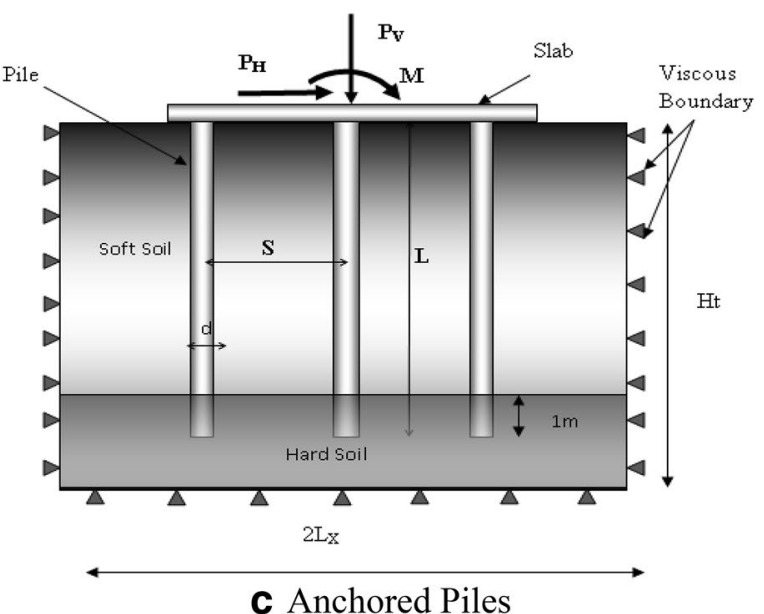

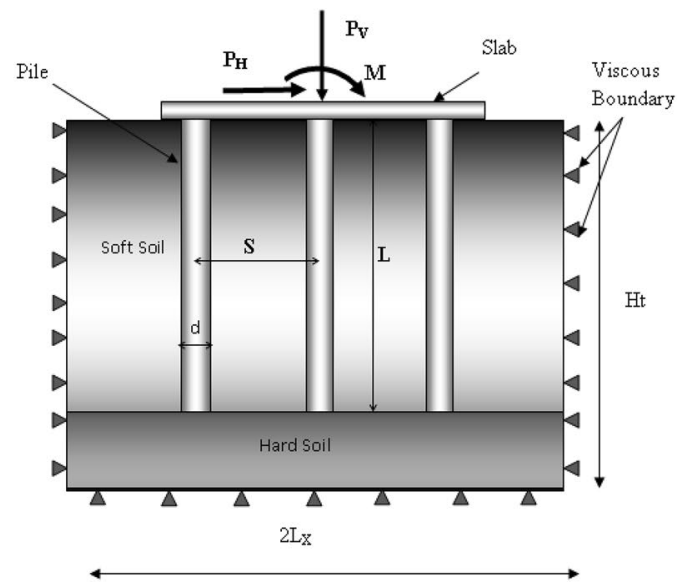

b Rested Piles

$\mathrm{L}=$ piles length

$\mathrm{S}=$ distance between axes

$\mathrm{t}=$ slab thickness

$\mathrm{d}=$ diameter of the piles

Fig. 3 Studied systems
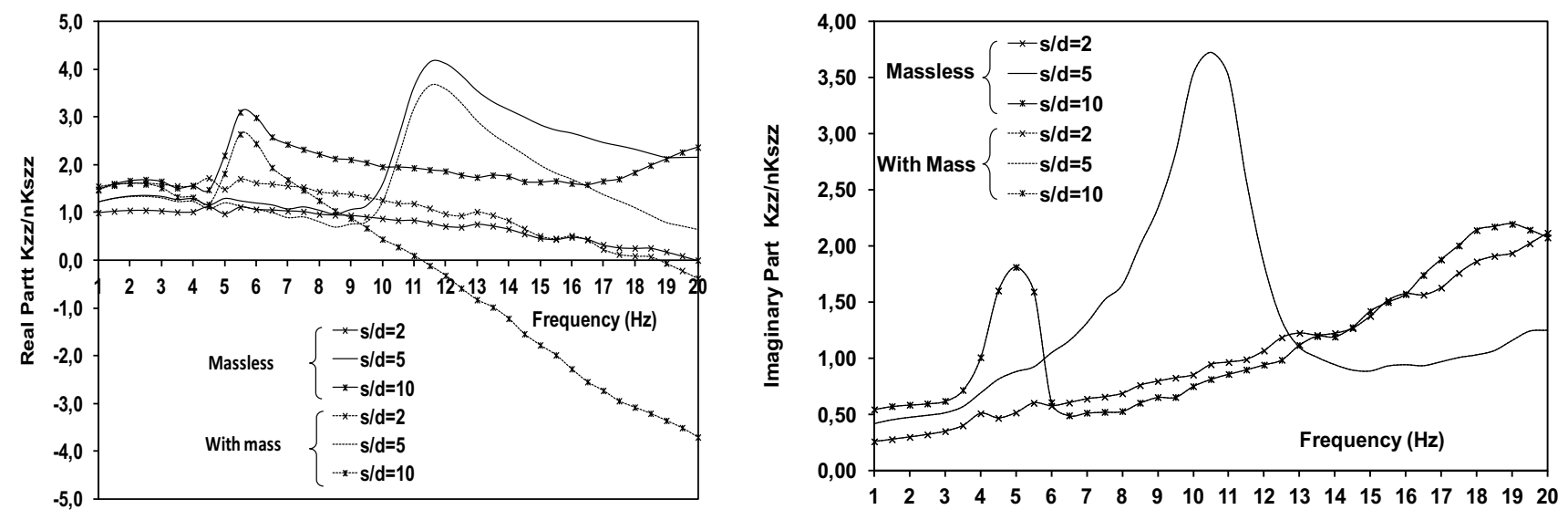

Fig. 4 Inertial effect for the vertical impedance $K_{z z}$ (group of 4 floating piles) 

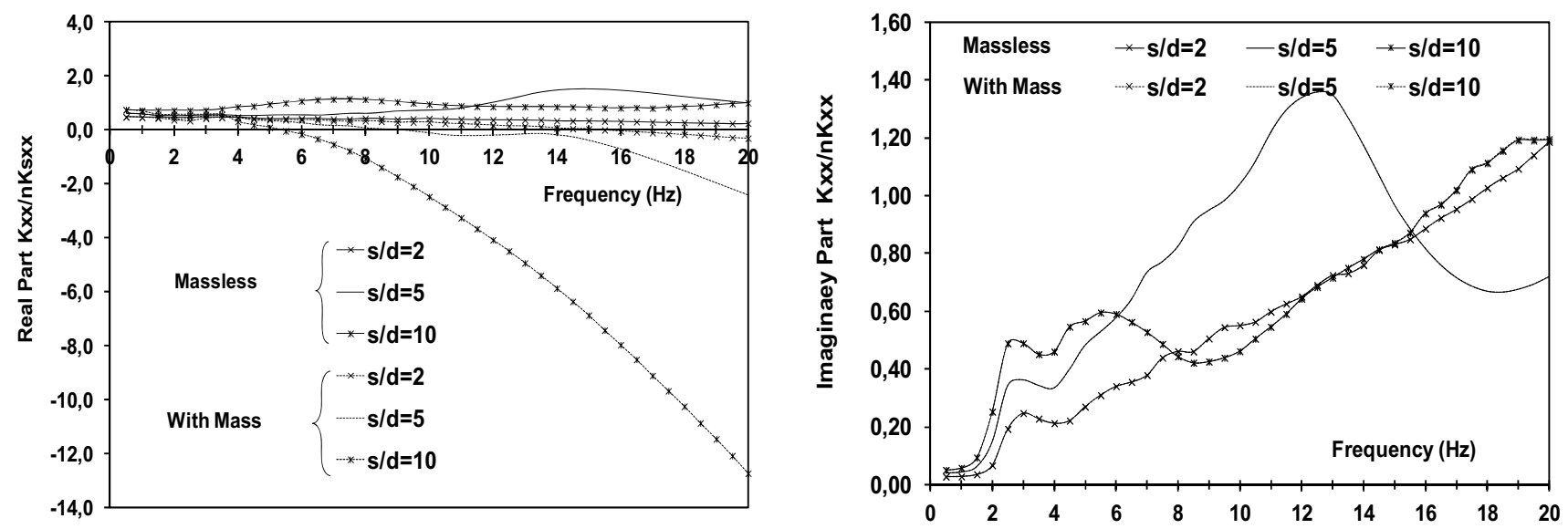

Fig. 5 Inertial effect for the horizontal impedance $K_{x x}$ (group of 4 floating piles)

Table 2 Evolution of the horizontal and vertical dynamic impedances under the inertial effect

\begin{tabular}{|c|c|c|c|c|c|}
\hline \multirow{2}{*}{$\begin{array}{l}\text { Fre- } \\
\text { quency } \\
(\mathrm{Hz})\end{array}$} & \multirow[t]{2}{*}{$s / d$} & \multicolumn{2}{|c|}{ Vertical impedance $K_{z z}$} & \multicolumn{2}{|c|}{$\begin{array}{l}\text { Horizontal impedance } \\
K_{x x}\end{array}$} \\
\hline & & Massless & With mass & Massless & With mass \\
\hline 20 & 5 & 2.15 & 0.64 & 0.98 & -2.427 \\
\hline 20 & 10 & 2.36 & -3.70 & 0.98 & -12.73 \\
\hline
\end{tabular}

\section{Influence of the anchoring conditions at the pile toe}

In this section, three configurations are considered depending on the relative position of the piles toe to the hard soil layer (Fig. 3). Floating piles, rested piles and anchored piles in the hard soil layer are considered. The vertical and horizontal dynamic impedances are calculated by the same principle and for a massless slab $(M=0)$. Figures $6,7,8$, 9,10 and 11 show the influence of the fixing conditions on the variation of the dynamic impedances as a function of the frequency.

\section{Vertical impedance}

Figures 6, 7 and 8 show the influence of the support layer rigidity on one hand and the influence of the fixing conditions on the other hand for different value of the $s / d$ ratio. Fixing the piles on the support layer increases the dynamic rigidity of the soil-pile-slab system especially for the ratios $s / d=2$ and 10 (Figs. 6 and 8). For the three $s / d$ ratios, the dynamic rigidity of the anchored piles is greater than the ones of the rested piles. The latter is superior to the ones of the floating piles. The vertical dynamic impedance for the anchored piles case is two times the one of the floating piles one for the ratio $s / s=2-10$. The effect of the support layer on the damping is not negligible. The presence of a rigid layer induces a reduction of the damping especially for high $s / d$ ratios and frequency (Fig. 8). The obtained results show
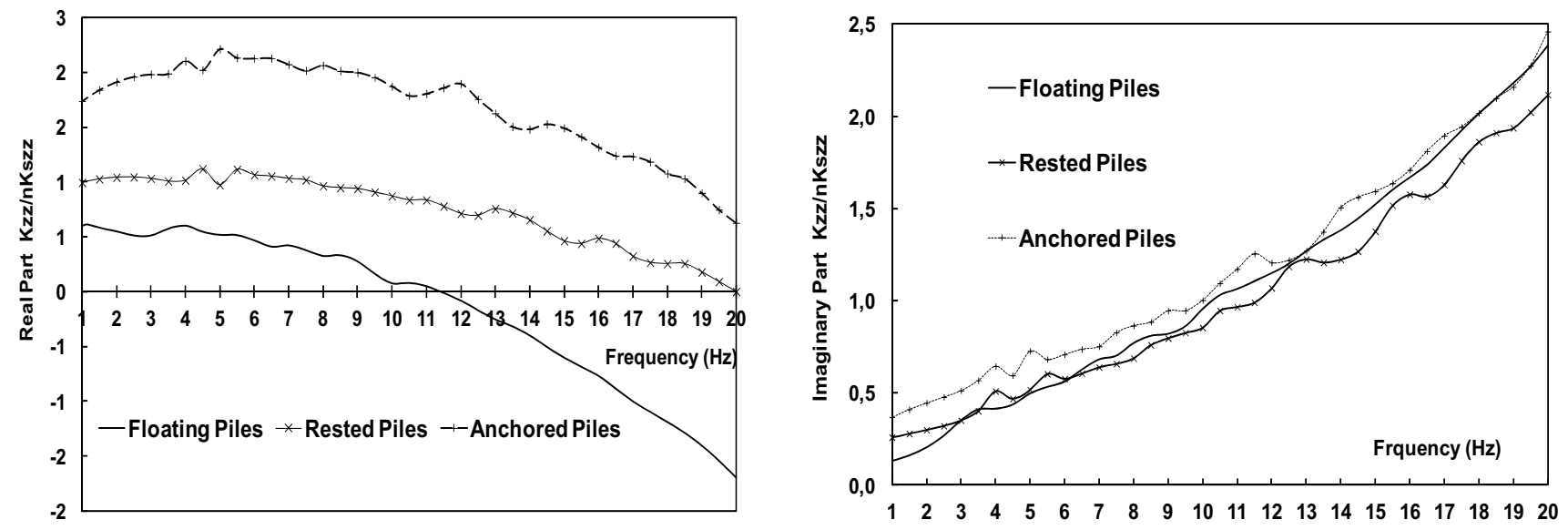

Fig. 6 Influence of the piles anchoring conditions on the vertical impedances $(s / d=2)$ 

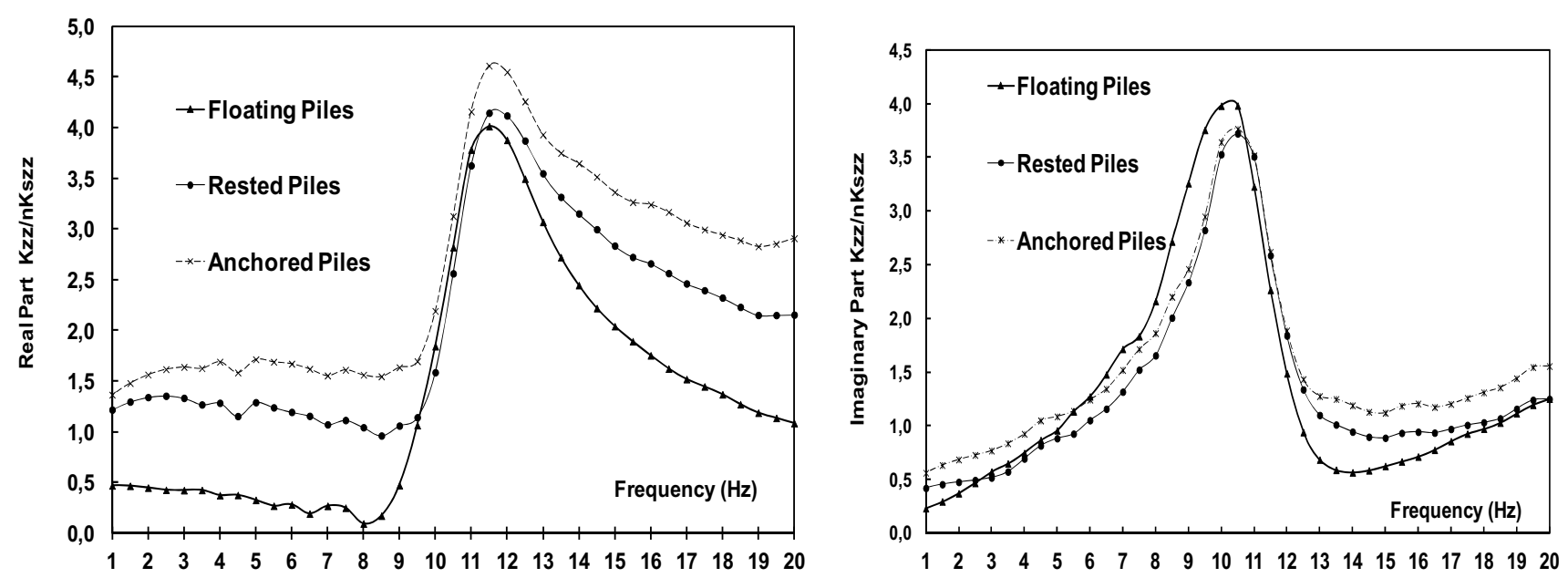

Fig. 7 Influence of the pile anchoring conditions on vertical impedance $(s / d=5)$
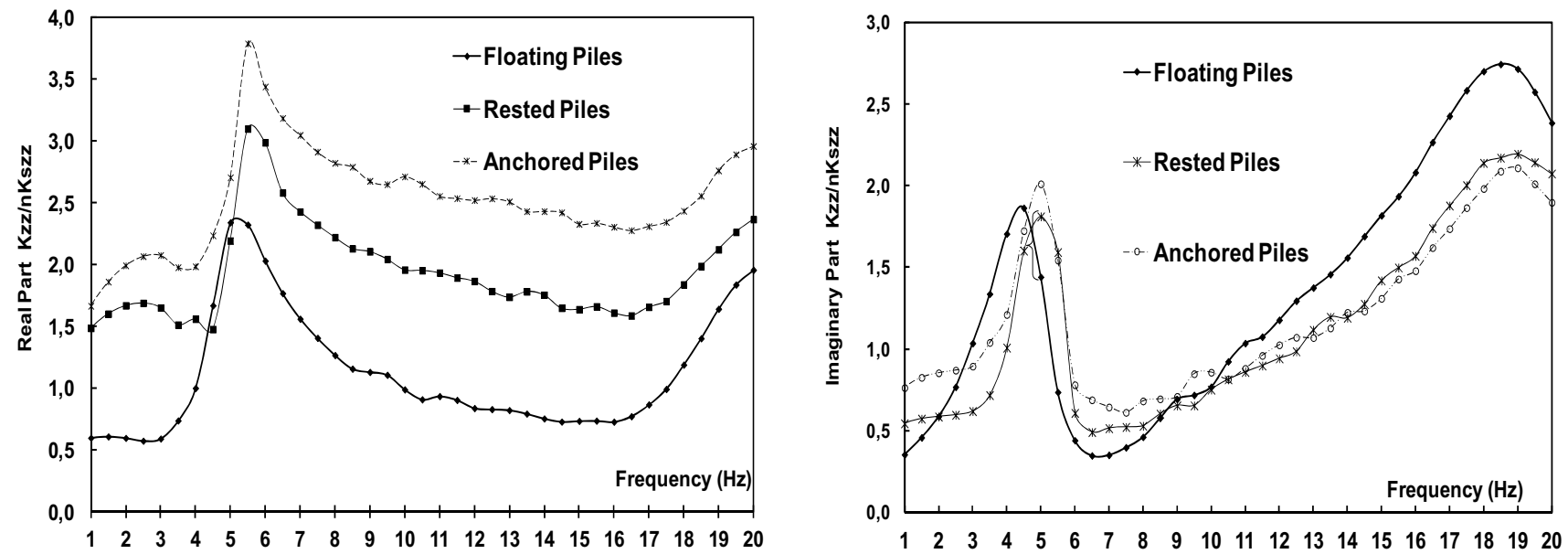

Fig. 8 Influence of the pile anchoring conditions on the vertical impedances $(s / d=10)$
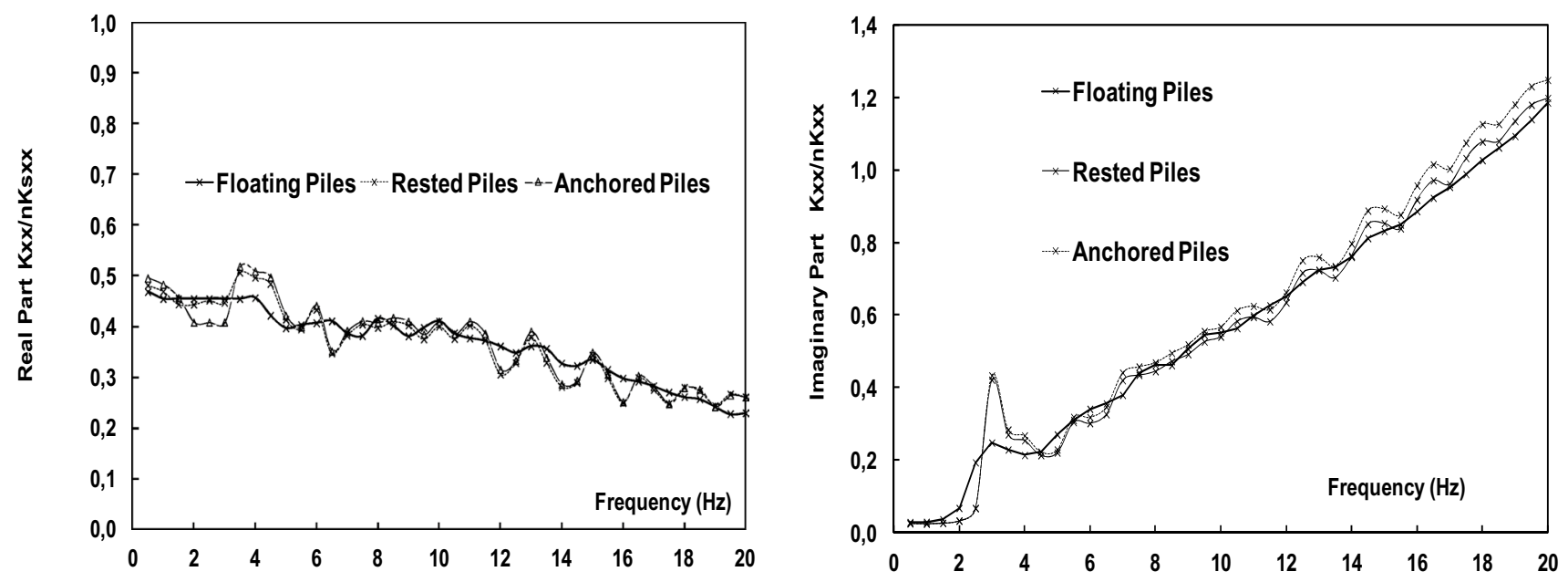

Fig. 9 Influence of the anchoring conditions of pile on horizontal impedance $s / d=2$ 

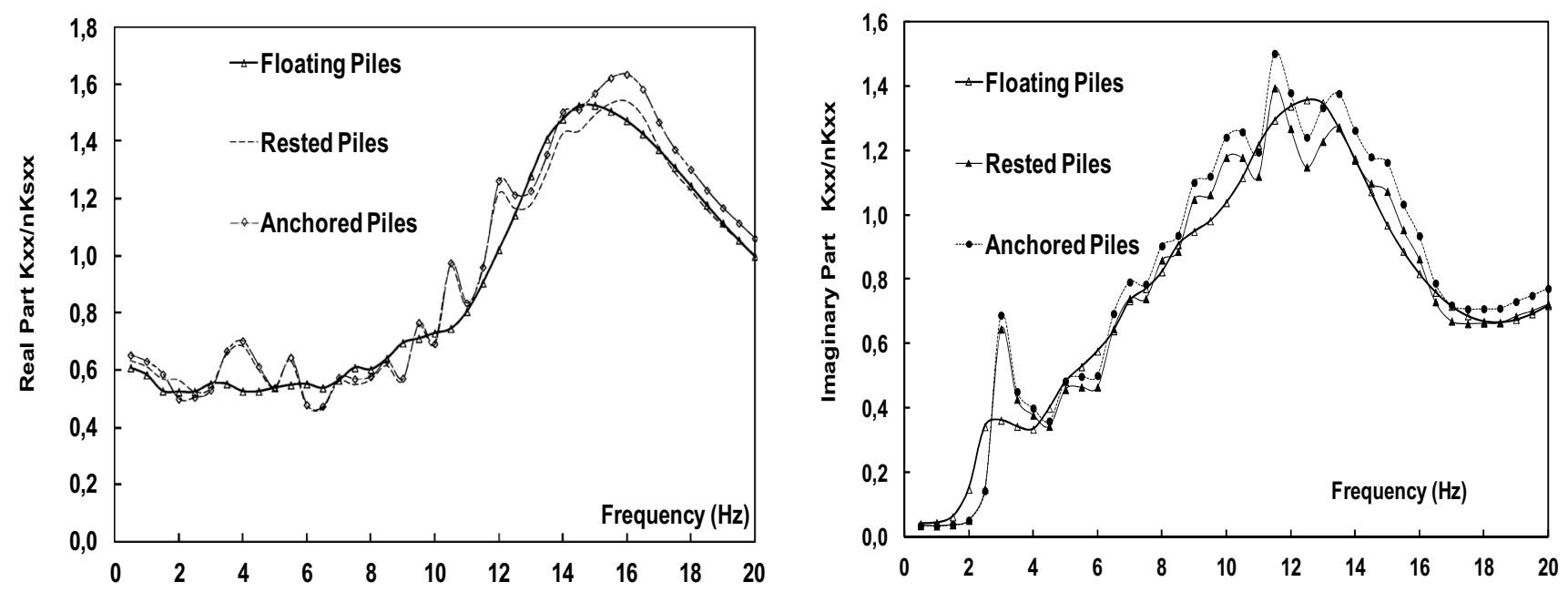

Fig. 10 Influence of the pile anchoring conditions on the horizontal impedances $(s / d=5)$
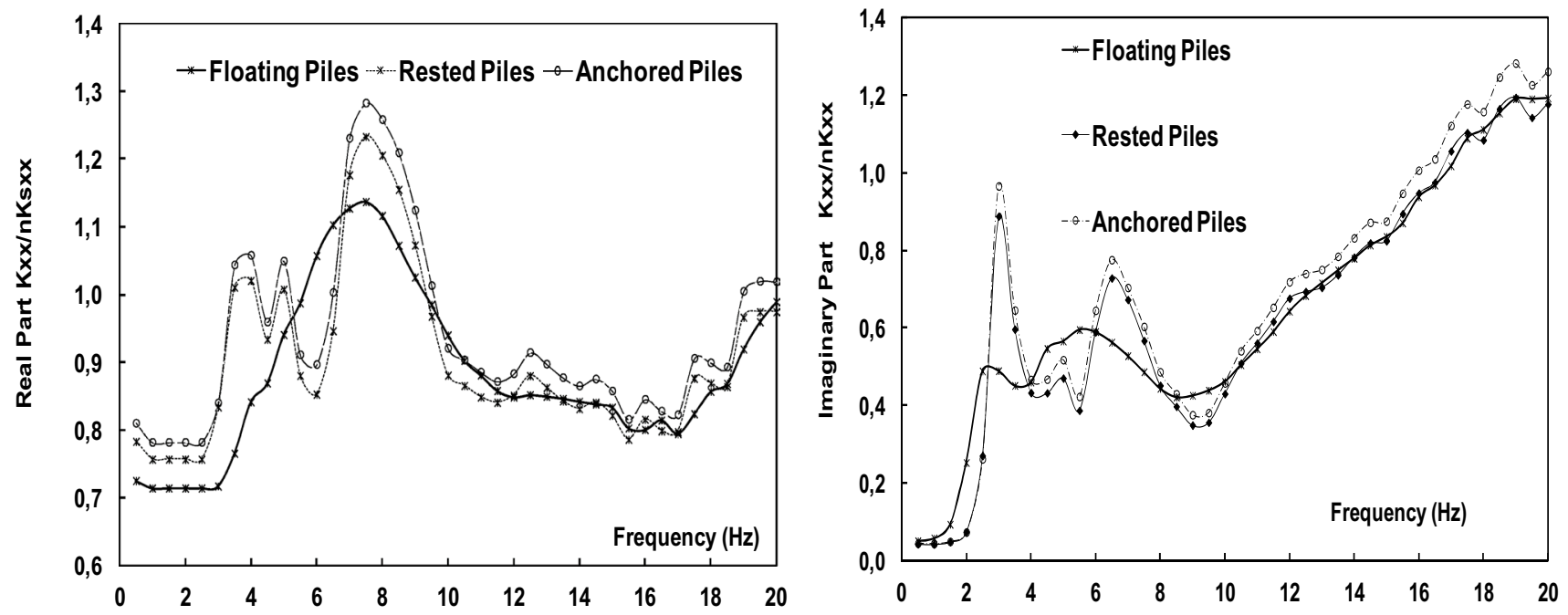

Fig. 11 Influence of the pile anchoring conditions for the horizontal impedance $(s / d=10)$

that anchoring piles on the rigid layer is the best solution, therefore the anchoring of the piles is not a negligible factor in the deep foundation.

\section{Horizontal impedance}

The horizontal dynamic impedances of soil-piles-slab system are calculated by applying a horizontal load on a half-model. The size of the half-model is $40 \times 20 \times 15 \mathrm{~m}^{3}$ Fig. 2c.

Figures 9, 10 and 11 show the influence of the fixing conditions of the piles on the horizontal impedances $K_{x x}$. For low ratios $s / d=2$, Fig. 9 shows some peaks of resonance due to the reflection of the waves at the level of the hard soil and the fixing effect of the piles in the hard soil layer. The dynamic stiffness and the horizontal damping are increased as a function of the fixing of the piles and even the system frequency is modified (Figs. 10 and 11).

The horizontal impedances are slightly affected by the fixing conditions. A remarkable difference was noted between the floating system, the rested and the anchored systems from the frequency of $8 \mathrm{~Hz}$ and the ratio $s / d=10$, in which we can note a considerable increase of 0.2 times the $K_{\mathrm{s}}$ (static impedance). In general the real part and imaginary part of the horizontal dynamic impedances are slightly affected by the fixing conditions compared to vertical dynamic impedances. 
The dynamic impedances are strongly attenuated at high frequencies, which can result in the occurrence of resonance peaks and the amplitude of resonance becomes more damped. The latter case occurs, if the depth of the piles is relatively large. Increasing the depth of the piles can induce a considerable increase of the soil contact surface. The phenomenon of wave refection is then larger. Moreover, there is an increase of the soil mass that participates in the vibratory movement. So, as the soil is damped, the movement will be damped especially for high frequencies.

\section{Group effect}

In this part, the rested piles system on the hard layer soil is considered and the number of piles varies between $2 \times 2,3 \times 3,4 \times 4$ and $5 \times 5$. The dynamic impedances of the soil-pile-slab system is calculated by applying a dynamic load at the center of the slab presented in Fig. 2a, $\mathrm{c}$, respectively. The following figures show the influence of the position of pile and the group effect on the dynamic impedance of the soil-pile-slab system.

\section{Vertical impedance}

The Figs. 12, 13 and 14 show the pile group influence on the dynamic impedances for ratios $s / d=2,5$ and 10 ; the dynamic impedances are severely affected by the increase of the piles number. The increase of dynamic stiffness is proportionally increasing with the piles number. The rate of increase is important especially for the ratios $s / d=5$ and 10 , but this variation is not uniform and depends on the considered pile group. The vertical dynamic impedance of a $3 \times 3$ piles group is higher of around 1.14 times the $K_{\mathrm{s}}$ than for the $2 \times 2$ one. It is lower than the impedance of a $4 \times 4$ pile group of 0.44 times the $K_{\mathrm{s}}$. The dynamic impedance value of the latter group is $5 \%$ lower than the one of the $5 \times 5$ pile group. The rigidity of the system becomes important
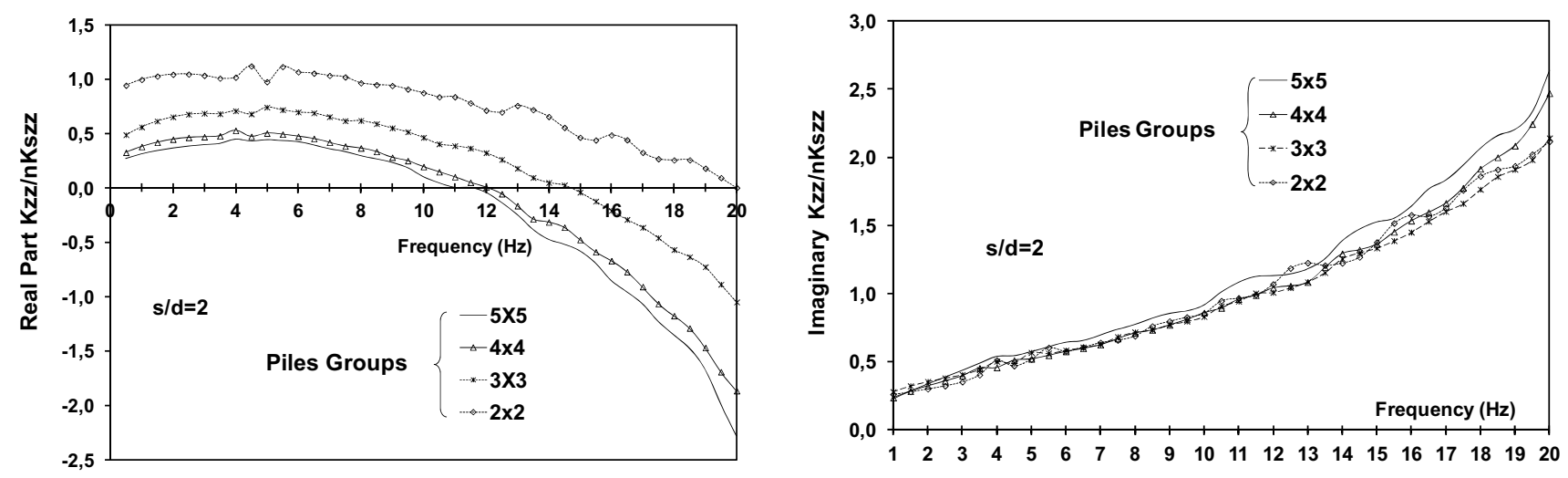

Fig. 12 Vertical impedance $K_{z z}$ of different pile groups $(s / d=2)$
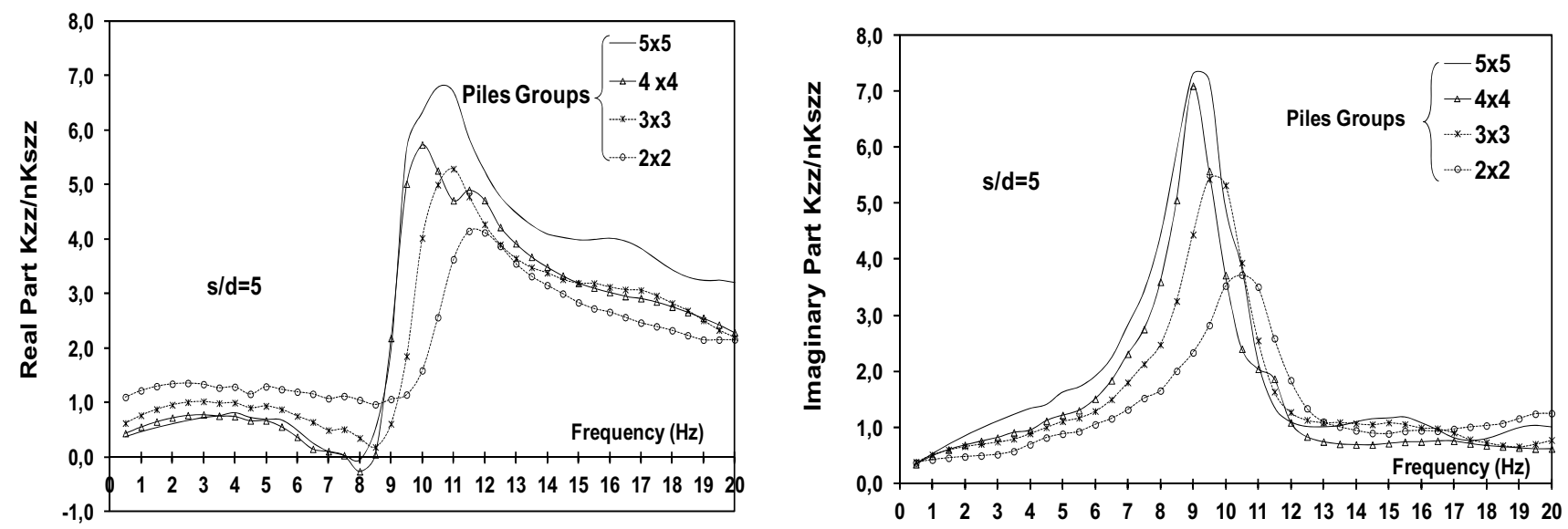

Fig. 13 Vertical impedance $K_{z z}$ of different pile groups $(s / d=5)$ 


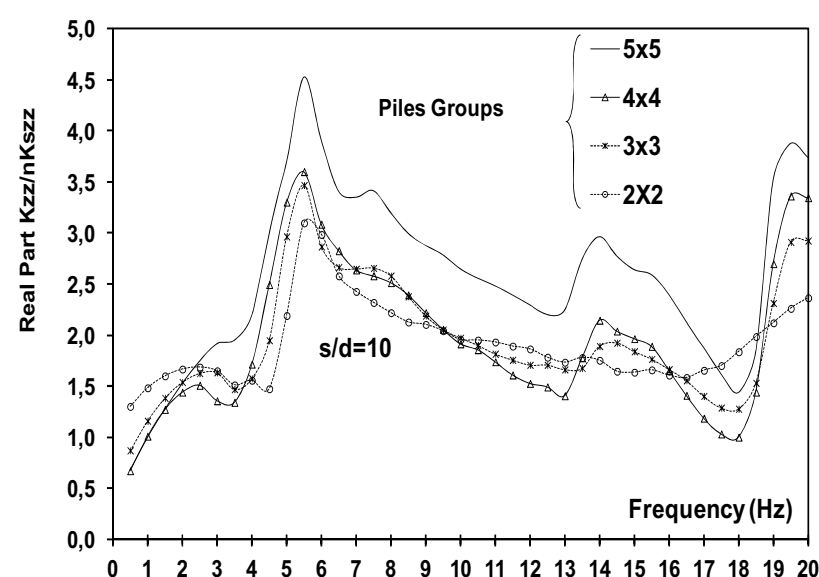

Fig. 14 Vertical impedance $K_{z z}$ of different pile groups $(s / d=10)$

for a high number of piles and the damping is affected in a significant way. The obtained results show that if the piles are quite numerous, the soil-pile-slab system becomes more rigid and more damped especially for ratios $s / d$ greater than 2 (Figs. 13, 14).

From the group of $4 \times 4$ piles, the resonance peaks are appearing for high frequencies. These peaks are induced by the reflection of the waves at the level of the foundation piles and the hard layer which constitutes a rigid block (Fig. 14).

\section{Horizontal impedance}

Figures 15 and 16 show the piles group effect on the horizontal dynamic response of rested piles for ratios $s / d=5$ and 10. Contrary to the vertical impedance case, the obtained results for horizontal impedances show that for low frequencies, the dynamic rigidity of the soil-pile-slab system decreases as a function of the piles number increase. The rate of increase is lower than the one of the vertical impedance

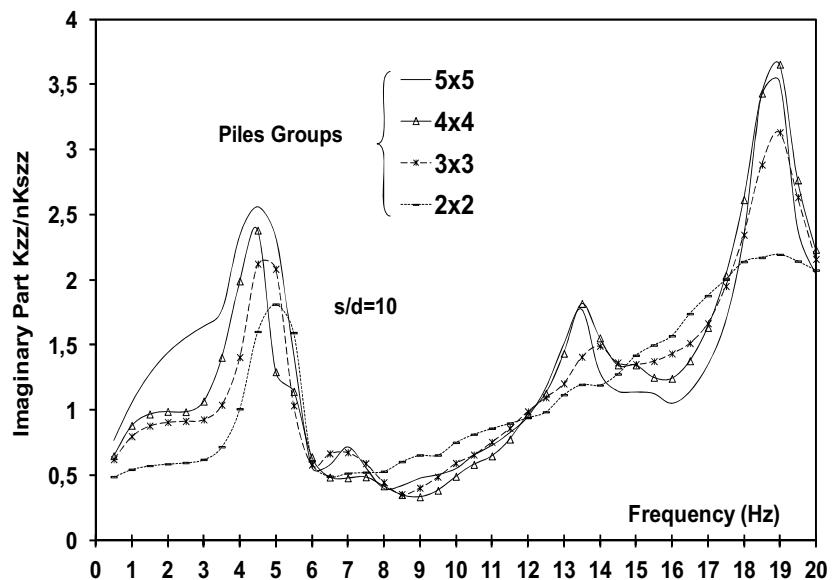

which is about 0.3 times the $K_{\mathrm{s}}$ for the stiffness and damping. However, for high frequencies the dynamic stiffness is increasing as a function of the piles number increase. This is probably due to the vibrating mass increase of the pilesoil block. The damping is strongly affected by the group effect. With a higher number of the piles, the soil-piles-slab system becomes more damped for low frequencies. For the ratio $s / d=10$, the increase of the dynamic stiffness and of the damping is proportional to the number of piles increase (Fig. 17).

\section{Conclusion}

In this study, a 3-D FEM dynamic analysis of soil-piles-slab systems embedded in a homogeneous isotropic visco-elastic soil are presented. The developed numerical models permitted the calculation of dynamic impedance functions (vertical and the horizontal). The
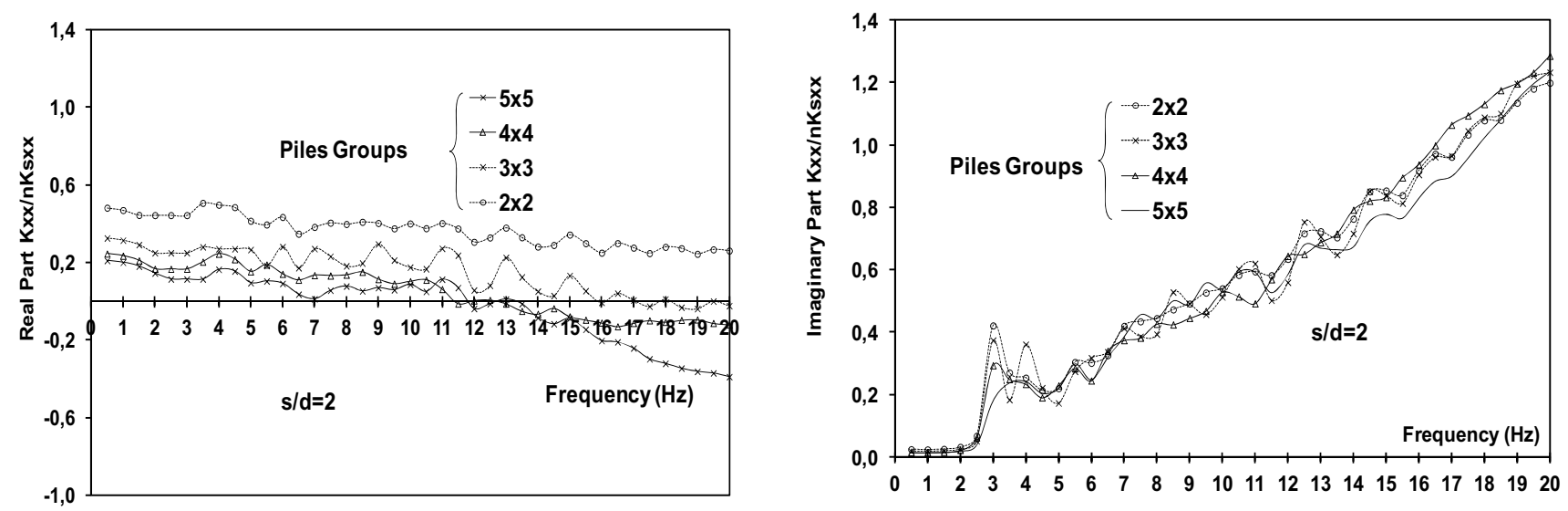

Fig. 15 Horizontal impedance $K_{x x}$ of different pile groups $(s / d=2)$ 

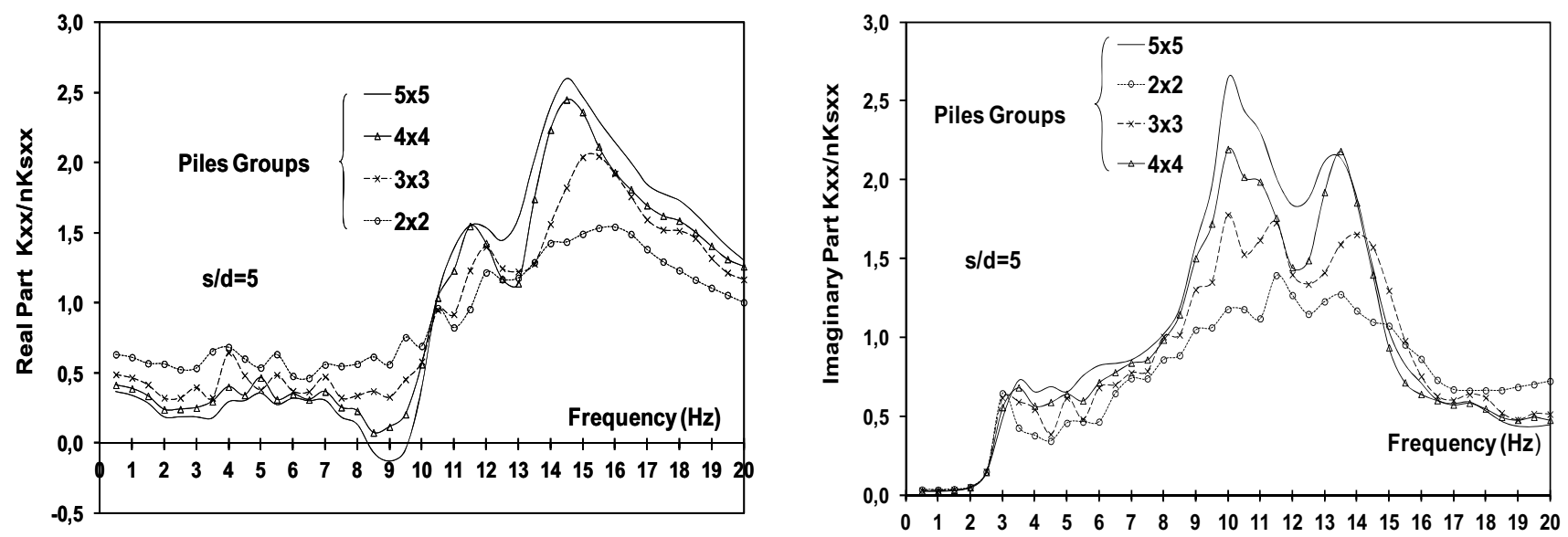

Fig. 16 Horizontal impedance $K_{x x}$ of different pile groups $(s / d=5)$
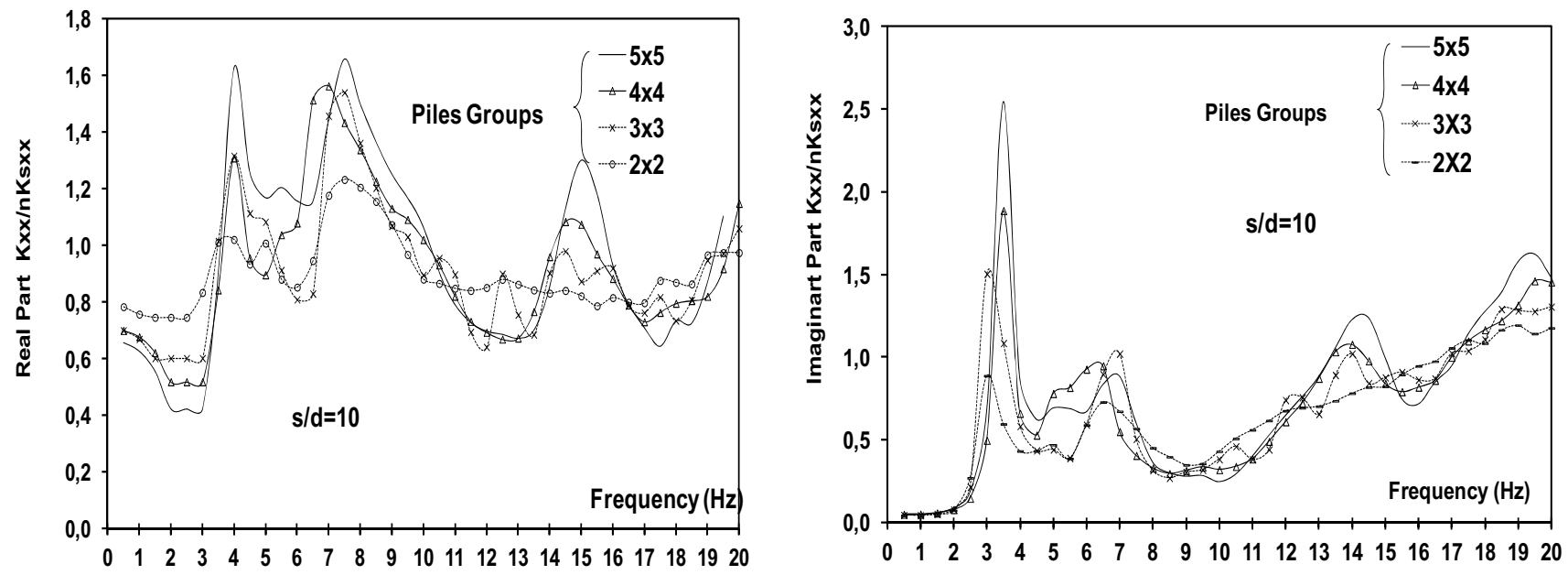

Fig. 17 Horizontal impedance $K_{x x}$ of different pile groups $(s / d=10)$

soil-pile-slab systems were simulated with different pile toe conditions. The evolution of the vertical and horizontal dynamic impedance as a function of the frequency and the influence of fixing conditions on the effect of the pile groups on the dynamic impedances has been studied. The influence of the $s / d$ ratio, the inertial effect of the slab and the influence of the hard soil layer on the dynamic impedances were presented.

The inertial effect of the slab affects the dynamic impedance terms in a very significant way. The stiffness terms (real part of the dynamic impedance) are strongly attenuated for relatively high $s / d$ ratios, mainly for high frequencies. These terms become negative after a certain frequency. On the other hand, the damping terms are not affected by the inertial effect.

The effect of the substratum rigidity affects the dynamic impedances in an important way. The results showed that the anchored piles have a steeper behavior than the rested piles and the floating piles. Increasing the depth of the piles can induce a considerable increase of the soil contact surface. Therefore, there is an increase of the soil mass that participates in the vibratory movement. The results show that the anchored piles in the rigid layer give the best solution; therefore, the anchoring of the piles is not a negligible factor in the case of deep foundations.

Open Access This article is distributed under the terms of the Creative Commons Attribution 4.0 International License (http://creativeco mmons.org/licenses/by/4.0/), which permits unrestricted use, distribution, and reproduction in any medium, provided you give appropriate credit to the original author(s) and the source, provide a link to the Creative Commons license, and indicate if changes were made. 


\section{References}

Ai ZY, Liu CL, Wang LJ, Wang LH (2016) Vertical vibration of a partially embedded pile group in transversely isotropic soils. Comput Geotech 80:107-114

Aubry D, Clouteau D (1992) A subdomain approach to dynamic soilstructure interaction. In: Earthquake engineering and structural dynamics, pp 251-272 (Ouest editions/AFPS, Nantes, France)

Coda HB, Venturini WS (1999) On the coupling of 3D BEM and FEM frame model applied to elastodynamic analysis. Int J Solids Struct 36:4789-4804

Coda HB, Venturini WS, Aliabadi MH (1999) A general 3D BEM/ FEM coupling applied to elastodynamic continua/frame structures interaction analysis. Int J Numer Meth Eng 46:695-712

Code-Aster (2010) Version 10.2. http://www.code-aster.org/utilisation/ non-french.ph.pNon-French0048103.0.26/Code_AsterResources

Emani PK, Maheshwari BK (2009) Dynamic impedances of pile groups with embedded caps in homogeneous elastic soils using CIFECM. Soil Dyn Earthq Eng 29:963-973

Kattis SE, Polyzos D, Beskos DE (1999a) Vibration isolation by a row of piles using a 3-D frequency domain BEM. Int J Numer Meth Eng 46:713-728

Kattis SE, Polyzos D, Beskos DE (1999b) Modelling of pile wave barriers by effective trenches and their screening effectiveness. Soil Dyn Earthq Eng 18:1-10

Kausel E, Whitmaand RV, Elsabee F, Morray JP (1978) The spring method for embedded foundation. Nuclear Eng Des 48:377-392

Kaynia AM (1982) Dynamic stiffness and seismic response of pile groups. Research Report R82-03, Order No. 718, Cambridge, Massachusetts

Kaynia AM, Kausel E (1991) Dynamics of piles and pile groups in layered soils. Soil Dyn Earthq Eng 10(8):386-401

Kouroussis G, Anastasopoulos I, Gazetas G, Verlinden O (2013) Threedimensional finite element modelling of dynamic pile-soil-pile interaction in time domain. In: 4th ECCOMAS Themat. Conf. Comput. Methods Struct. Dyn. Earthq. Eng. Kos Island, Greece

Kuhlemeyer RL, Lysmer J (1973) Finite Element method accuracy for wave propagation problems. J Soil Mech Found Div ASCE 99(SM5):421-427

Liu Y, Wang X, Zhang M (2014) Lateral vibration of pile groups partially embedded in layered saturated soils. Int J Geomech 15(4):04014063
Liu CL, Ai ZY (2017) Vertical harmonic vibration of piled raft foundations in layered soils. In: International journal for numerical and analytical methods in geomechanics

Maeso O, Aznarez JJ, Garcia F (2005) Dynamic impedances of piles and groups of piles in saturated soils. Comput Struct 83:769-782

Mamoon SM, Kaynia AM, Banerjee PK (1990) Frequency domain dynamic analysis of piles and pile groups. J Eng Mech ASCE 116(10):2237-2257

Messioud S, Sbartai B, Dias D (2016) Estimation of dynamic impedance of the soil-pile-slab and soil-pile-mattress-slab systems. In: International journal of structural stability and dynamics, $p$ 1750057

Messioud S, Okyay US, Sbartai B, Dias D (2016b) Dynamic response of pile reinforced soils and piled foundations. Geotech Geol Eng 34(3):789-805

Mylonakis G, Gazetas G (1999) Lateral vibration and internal forces of grouped piles in layered soil. J Geotech Earthq Eng 125:16-25

Okyay US, Dias D, Billion P, Vandeputte D, Courtois A (2012) Impedance functions of slab foundations with rigid piles. Geotech Geol Eng 30(4):1013-1024

Padron LA, Aznarez JJ, Maeso O (2007) BEM-FEM coupling model for the dynamic analysis of piles and pile groups. Eng Anal Bound Elem 31:473-484

Pecker A (1984) Dynamique des sols. Presses de l'Ecole Nationale des Ponts et Chaussées

Sawant VA, Ladhane KB (2012) Dynamic response of pile groups in series and parallel configuration. Struct Eng Mech 41(3):395-406

Vinciprova F, Aznarez JJ, Maeso O, Oliveto G (2003) Interaction of BEM analysis and experimental testing on pile-soil systems. In: Davini C, Viola E (eds) Problems in structural identification and diagnostic: general aspects and applications. Springer, Berlin, pp 195-227

Wolf JP (1994) Foundation vibration analysis using simple physical model. PTR Prentice Hall, Upper Saddle River

Publisher's Note Springer Nature remains neutral with regard to jurisdictional claims in published maps and institutional affiliations. 